\title{
Can renal stone size and the use of the nephrolithometric system increase the efficacy of predicting the risk of failure of percutaneous nephrolithotripsy?
}

\section{O tamanho do cálculo renal e o uso do sistema nefrolitométrico podem aumentar a eficácia de predizer o risco de falha de nefrolitotripsia percutânea?}

Eduardo Medina Felici, AsCbC-RJ1; André luiz Lima Diniz'; Tomas Accioly Souza1; Luciano Alves Favorito1; José Anacleto Dutra RESENDE JÚNIOR ${ }^{1}$.

\begin{abstract}
A B S T R A C T
Objective: to verify the association of success rate of percutaneous lithotripsy, Guy score and size of the stone. Methods: one hundred patients submitted to percutaneous nephrolithotripsy were evaluated. All stones were classified according to Guy Score. Patient free of stone was considered when residual fragments were $\leq 2 \mathrm{~mm}$. Results: according to guy Score, 54\% were score 1 (Group 1), $18 \%$ score 2 (Group 2), 15\% score 3 (Group 3), and 13\% score 4 (Group 4). Success was observed in $77.77 \%$ in Group 1, 27.77\% in group 2, 26.6\% in Group 3, and 7.69\% in Group 4. In patients with Guy score 1, there was statistical significance of prediction of free stone rate when evaluated according to the size of the stone. Among groups 2, 3 and 4 there was no statistical significance, but it was observed a trend in relation to stone size, the bigger the higher the chance of residual fragments. Conclusion: nephrolithometry by Guy Score and size of the stone are single predictors of success of percutaneous nephrolithotripsy. Stone size may influence success rate of patients with Guy Score 1.
\end{abstract}

Keywords: Kidney Calculi. Nephrolithiasis. Lithotripsy. Propensity Score.

\section{INTRODUCTION}

$D$ ercutaneous nephrolithotripsy (PNL) is one of the main methods to treat renal lithiasis, particularly stones with more than $2 \mathrm{~cm}$ diameter ${ }^{1}$. Although total fragmentation is expected, it is not always possible, and additional procedures are necessary, in special in staghorn or multiple calix stones ${ }^{2}$. Size of the stone, calix involvement, calix and pelvic anatomy, and anatomic malformations orient the feasibility of different treatments and impact surgical results ${ }^{3,4}$. The use of a nephrolithometric validated system may improve stratification and care of patients, and allow for better therapeutic decisions ${ }^{5}$. However, we believe that this system must take into account stone characteristics, particularly size, for efficient evaluation of PNL.

The objective of the present work is to verify the association of success rate of percutaneous nephrolithotripsy, Guy Score and stone size.

\section{METHODS}

This is a retrospective, cross-sectional study approved by the Ethical Committee of Hospital Federal da Lagoa, that reviewed the charts of 137 patients submitted to PNL by one of the authors, from January 2013 to August 2016. All patients signed a free informed consent form and were informed by the risks and benefits of the procedure. We included patients with renal stones bigger than $2 \mathrm{~cm}$ (higher diameter), or of any size, when previous treatments with extracorporeal lithotripsy (ESWL) or flexible ureteronephroscopy with laser were not possible. Patients with incomplete charts (stone characteristics, results) were not included. All patients received first generation cephalosporin for antibiotic prophylaxis.

PNL followed a standardized technique. Initially, an ureteral catheter was introduced endoscopically with the patient in lithotomy position. Next, pa-

1 - Hospital Federal da Lagoa, Urology Department, Rio de Janeiro, RJ, Brazil. 
tient was changed to ventral decubitus and percutaneous access was provided with the aid of a $C$ arch and retrograde pyelography. Path dilation was performed with Amplatz dilators until 30Fr. Nephroscopy was performed by a rigid nephroscope $28 \mathrm{~F}$ and, using a ultrasonic lithotripter, stone was fragmented, removed or aspirated. In the end of lithotripsy, a double J catheter was inserted, as well as a nephrostomy tube, that was removed after 24 hours. At $30^{\text {th }}$ day of post-operatory, it was obtained a KUB X-ray, and, if there were no residual stones, double J catheter was removed. In the $3^{\text {rd }}$ month, a control computer tomography scan (CT) was obtained to follow up and determination of success rate. If there were residual stones at the $X$ Ray, double J catheter was kept in place, CT scan was performed ( $<3$ months) and the patient was submitted to a new procedure. We considered therapeutic success (free of stones) when residual fragments were lower than $2 \mathrm{~cm}$, confirmed by CT.

We used the Guy Score nephrolithometric system (GS): GS1 - single stone in meso-renal region or inferior pole in patient with normal anatomy; GS2 single stone in superior pole, multiple stone in patient with normal anatomy, or single stone in patient with anatomic anomaly; GS3 - multiple stone and anatomic anomaly, diverticulum stone, or partial staghorn stone; GS4 - complete staghorn stone or any stone in patient with spina bifida or spinal trauma ${ }^{1}$. Aside from GS, we determined stone size using its bigger dimension at CT.

After preliminary data analysis, to search for gross errors and outliers identification, and normality test verification for each continuous variable (Kolmogorov-Smirnov), preliminary descriptive statistics was performed to characterize the sample. Non-gaussian distributed variables were submitted to non-parametric statistics. Person chi-square (or Fisher) was used to verify association between categorical variables. Student t test (parametric, considering Levene test for variance equality) and Mann-Whitney or Kruskal-Wallis tests (non-parametric) compared groups in relation to numeric variables. For multi-categorical analysis, we used Multinomial Logistic Regression, and for multivariable analysis we used the Cox regression test.

Graphics and statistical analysis were made by the software IBM $®$ SPSS $®$ Statistics Standard Grad
Pack 20 (NY, USA) for Windows® (IBM Corp. Released 2011. IBM SPSS Statistics for Windows, Version 20.0. Armonk, NY: IBM Corp.). Statistical results were considered significant when $p<0.05$ (bicaudal).

\section{RESULTS}

Thirty seven patients were excluded from the initial 137: 20 had no report of pre-operatory $C T$, ten no post-operatory CT and seven had not be submitted to post-operatory $\mathrm{CT}$. Among patients included in the study, 40 were male and 60 female. Mean age was 50.8 years and median 52 . Among men, mean age was 52.3 years and median 54. Among women, mean age was 49.7 years and median 51 years. Fifty one per cent of stones were located at left side and $49 \%$ at the right kidney.

Demographic data are presented at table 1.

When the greatest diameter of stones in different groups of GS were analyzed, the following means and confidence interval of 95\% were found: $\mathrm{SG} 1=20.2 \mathrm{~mm}$ (18.4 to $22.2 \mathrm{~mm}$ ); SG2=22.8mm (19.3 to $26.5 \mathrm{~mm}$ ); SG3 $=42.7 \mathrm{~mm}$ ( 37.5 to $48.5 \mathrm{~mm}$ ) and $\mathrm{SG} 4=60.8 \mathrm{~mm}$ ( 57.5 to $64.3 \mathrm{~mm}$ ). No differences were found between groups GS1 and GS2 ( $p=0.204)$, but when other groups were compared among them, there was statistical significance difference $(p<0.001)$ (Figure 1).

According to GS, among 54 patients of group 1,42 had no residual stone (77.8\%), and also six of 18 patients of group $2(27.8 \%)$ and four of 15 patients of group 3 (26.6\%); of 13 patients of group 4 , only one $(7.7 \%)$ had no residual stone. There was no statistical difference in the comparison of free stone rate according to gender or stone laterality. However, when success rates were analyzed according to GS and size of stone, it was possible to identify differences (Table 2).

When we evaluate the success rate for stratified stones as Guy 1, a higher chance of stone free status was identified, when compared to other Guy groups (Table 3).

When we perform a multivariable analysis (Cox Regression) to evaluate the influence of the size of stones in the rate success and of Guy score, in GS1 group, different from other groups, the relative risk 
(RR) was 0.02 for stones up to $2 \mathrm{~cm}$, RR of 0.14 for stones $2-2.9 \mathrm{~cm}, \mathrm{RR}$ of 0.34 for stones $3-3.9 \mathrm{~cm}, \mathrm{RR}$ of 0.68 for stones $4-4.9 \mathrm{~cm}$ and RR of 1.08 for stones $5 \mathrm{~cm}$. In group GS2, the relative risks were 0.13 for sto-

Table 1. Demographic data.

\begin{tabular}{|c|c|c|c|}
\hline & Variables & $\%$ & Cl 95\% \\
\hline \multicolumn{4}{|l|}{ Gender } \\
\hline & Female & 60.0 & $50.0-70.0$ \\
\hline & Male & 40.0 & $30.0-50.0$ \\
\hline \multicolumn{4}{|l|}{ Lateralidade } \\
\hline & Left & 51.0 & $41.0-61.0$ \\
\hline & Right & 49.0 & $39.0-59.0$ \\
\hline \multicolumn{4}{|l|}{ Sucess rate (stone free) } \\
\hline & Yes & 52.0 & $43.0-63.0$ \\
\hline & No & 48.0 & $37.0-57.0$ \\
\hline \multicolumn{4}{|l|}{ Guy Score } \\
\hline & 1 & 54.0 & $44.0-64.0$ \\
\hline & 2 & 18.0 & $10.0-26.0$ \\
\hline & 3 & 15.0 & $8.0-22.0$ \\
\hline & 4 & 13.0 & $7.0-20.0$ \\
\hline \multicolumn{4}{|l|}{ Size of Stone } \\
\hline & 1 a $1.9 \mathrm{~cm}$ & 28.0 & $20.0-37.0$ \\
\hline & 2 a $2.9 \mathrm{~cm}$ & 27.0 & $18.0-37.0$ \\
\hline & 3 a $3.9 \mathrm{~cm}$ & 13.0 & $7.0-20.0$ \\
\hline & $\geq 4 \mathrm{~cm}$ & 32.0 & $23.0-41.0$ \\
\hline
\end{tabular}

Cl 95\% - Confidence interval.

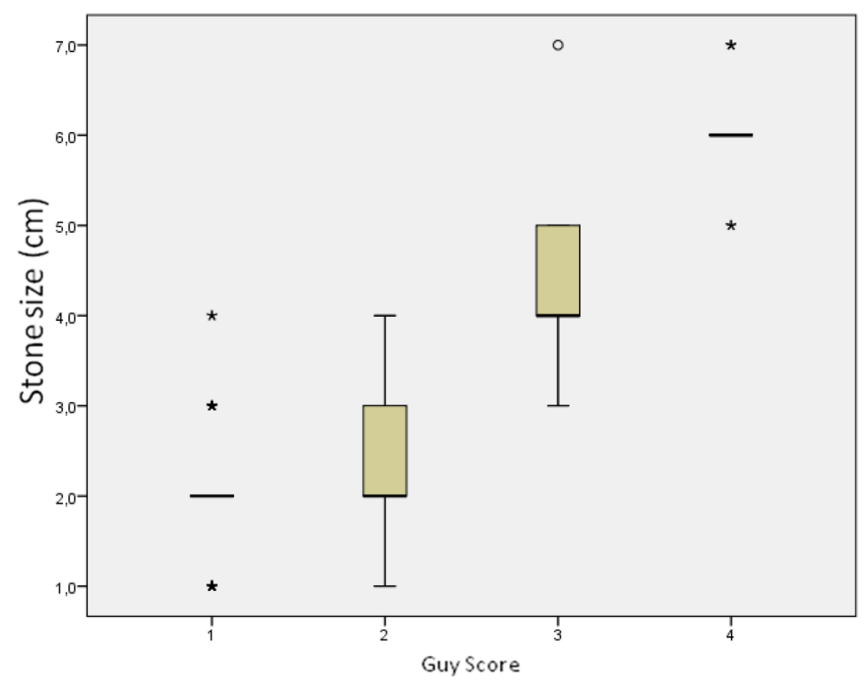

Figure 1. Box plot - Size of the stone in each Guy Score group.
Table 2. Sucess rate (free of Stone) in different groups.

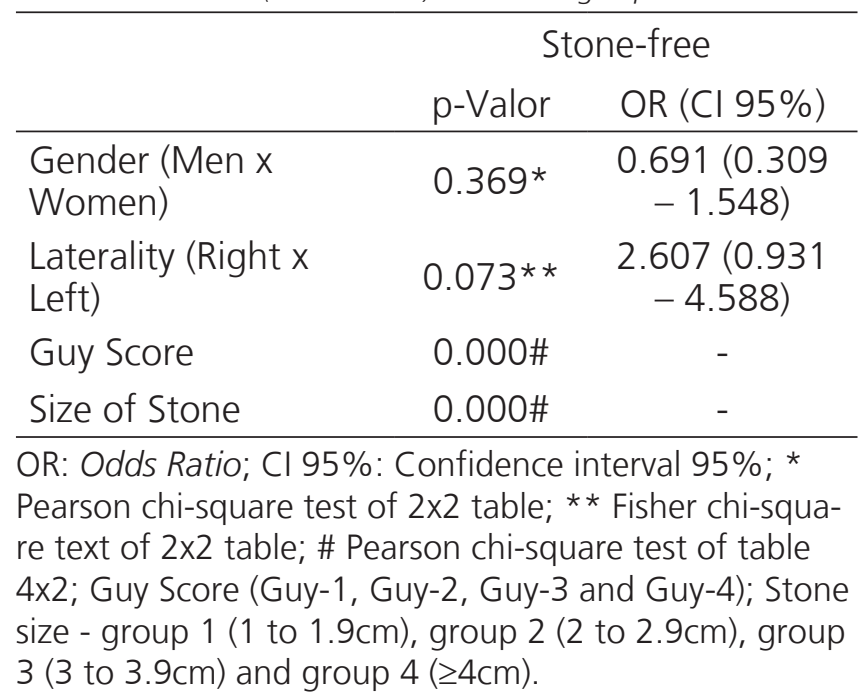


nes up to $2 \mathrm{~cm}$, RR 0.57 for stones $2-2.9 \mathrm{~cm}, \mathrm{RR} 0.89$ for stones $3-3.9 \mathrm{~cm}, \mathrm{RR} 1.27$ for stones $4-4.9 \mathrm{~cm}$ and RR 1.68 for $5 \mathrm{~cm}$ stones. In GS3, the relative risks were 0.15 for stones up to $2 \mathrm{~cm}$, RR 0.80 for stones $2-2.9$ $\mathrm{cm}, \mathrm{RR} 1.17$ for stones $3-3.9 \mathrm{~cm}$, RR of 1.28 for stones
$4-4.9 \mathrm{~cm}, \mathrm{RR}$ of 1.40 for stones $5-5.9 \mathrm{~cm}$ and $R R 2,50$ for $6 \mathrm{~cm}$ stones. For group GS4, RR was 0.15 for stones up to $2 \mathrm{~cm}, \mathrm{RR} 0.80$ for stones $2-2.9 \mathrm{~cm}, \mathrm{RR} 1.27$ for stones $3.3 .9 \mathrm{~cm}, \mathrm{RR} 1.72$ for stones $4-4.9 \mathrm{~cm}$ and $R R$ 1.72 for $5 \mathrm{~cm}$ stones (Figure 2).

Table 3. Success rate (free of stones) comparing Guy Score group 1 to other Guy score groups.

\begin{tabular}{cccc}
\hline & & \multicolumn{2}{c}{ Free of Stone } \\
\hline & & p-Valor & OR (CI 95\%) \\
\hline \multirow{3}{*}{ Guy Score vs. } & Guy Score 2 & $<0.001$ & $8.400(3.323-21.331)$ \\
& Guy Score 3 & $<0.001$ & $10.500(3.765-29.282)$ \\
& Guy Score 4 & $<0.001$ & $42.000(5.781-305.158)$ \\
\hline
\end{tabular}

OR- Odds Ratio; CI 95\%-Confidence interval 95\%; Multinodal Logistic Regression.

\section{DISCUSSION}

When we analyzed the influence of the stone size and success rate (free of stones) in each GS and among them, we observed that the higher the size of the stone, the higher the chance of the patient present residual stones. GS1 patients with stones bigger than $5 \mathrm{~cm}$ had a higher chance of residual stones. In GS2, GS3 and GS4 patients, the risk of residual stones was higher for stones bigger than $4 \mathrm{~cm}, 3 \mathrm{~cm}$ and $3 \mathrm{~cm}$, respectively.

Percutaneous access for the treatment of kidney stones was proposed 30 years ago by Fernstrom and Johansson ${ }^{6}$. With the improvement of the technique, nowadays, PNL replaced open surgery in the treatment of complex renal stones in many facilities ${ }^{7}$. Choice of surgical technique is based on the stone characteristics in image exams, particularly CT. Usually, stones bigger than $2 \mathrm{~cm}$ and $>1000 \mathrm{UH}$ (Hounsfield units) are candidate to percutaneous treatment ${ }^{8}$. Contrary to classic indications, stones lower than $2 \mathrm{~cm}$ and with difficult access, or complex staghorn stones may also be treated by this technique, as observed in our study.

Several methods of nefrolithometry were proposed to classify stones according to nature and position. The first was proposed by Thomas et al. ${ }^{1}$ using the
Guy Score. Smith et al. ${ }^{9}$ described the nephrolithometric nomogram CROES (Clinical Research Office of the Endourological Society). Okhunov et al. ${ }^{10}$ developed the score system S.T.O.N.E. Literature presents several comparisons of nephrolithometric methods, but there are no evidences with statistical significance that indicate the systematic use of a single one. Withington et al. ${ }^{11}$ made a literature review of these tools in the evaluation of stone complexities and success rates, in order to evaluate any evidences that favored one of them. This review showed no preference of a single system. However, evidences showed that GS was slightly superior. Labadie et al.12 compared each system in the same cohort to determine which was more predictive of surgical success. They concluded that all classification systems could equally predict stone-free rate. Guy and S.T.O.N.E nephrolithometries estimated better blood loss and hospitalization time. Vicentini et al. ${ }^{13}$ published a study that affirmed that GS, based on CT scans, predicted with higher accuracy success and complications rates after PNL. Since it is very simple to apply, we chose GS nephrolithometry score associated to size of stones to analyze our cohort.

In Vicentini et al. ${ }^{13}$ study, the greatest stone diameters were different among groups, statistically significant (SG1=21.4mm; SG2=26.5mm; SG3 $=31.4 \mathrm{~mm}$ 

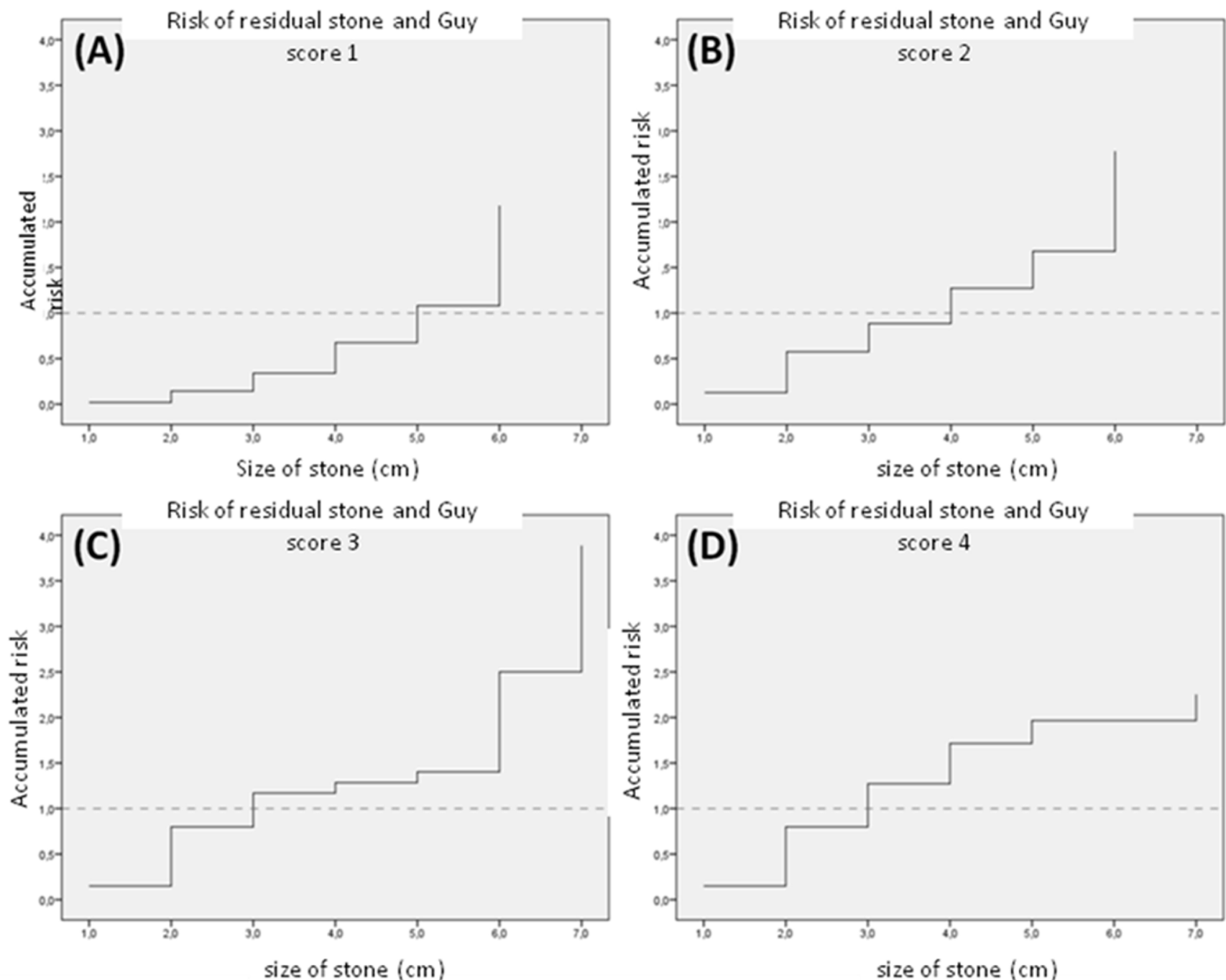

Figure 2. Cox Regression - Residual stone risk based on the size of stones (dependent variable) according to co-variable 'free of stones" and of the following variables "state/event": A) Guy 1 versus [Guy 2 + Guy 3 + Guy 4]; B) Guy 2 versus [Guy 1 + Guy 3 + Guy 4]; C) Guy 3 versus [Guy 1 + Guy 2 + Guy 4]; D) Guy 4 versus [Guy 1 + Guy 2 + Guy 3].

and SG4=50.5mm). In our work, there were differences only between GS1 and GS2 groups ( $p=0.204)$. When patients were divided in groups according do GS and biggest diameter, the stone-free rate was evaluated, and stratified GS1 group was an independent predictive factor for stone-free rate $(p<0.001)$. We also observed that the smaller the stone, the higher the chance of success $(p<0.001)$. When patients were classified as GS2, GS3 and GS4, there was a higher risk of unsuccess (with residual stones) for stones bigger than $4 \mathrm{~cm}, 3 \mathrm{~m}$ and $3 \mathrm{~cm}$, respectively. But since our sample in these groups was small, this information should be cautiously analyzed.

Alobaidy et al..$^{14}$ observed that, with the increase of stone size and complexity, the rate of stone-free patients lowered, but did not correlate this finding to Guy parameters. Aside from predicting stone-free rate, GS can predict with good accuracy the rate of complications. Vicentini et al. ${ }^{13}$ reviewed 155 PNL and showed statistical significance of Guy score and blood transfusion rate and surgery time. Bozkurt et al. ${ }^{15}$ also identified a statistical significant relation between GS and post-operatory complication rate.

In 2008, Tefekli et al. ${ }^{16}$ evaluated 811 patients and proposed an adaptation of Modified Clavien sco$\mathrm{re}^{17}$ for analysis of PNL complications. They divided the severity of complications based on stone complexity and 
did not find any significant relation. In our populational analysis, we identified eight major complications (Modified Clavien grades $3 a$ to $4 b)^{17}$, but without statistical significance in relation to GS. Absence of complications grades 1 and 2 reflects a bias inherent to retrospective analysis, since they are minor complications, self-limited and with low impact on clinical success, and not well reported at the charts. In our sample, no patient received blood transfusion. Tefekli et al. ${ }^{16}$ reported that only $2.8 \%$ of patients had post-operatory fever, relating this to the use of antibiotic prophylaxis in all their patients, as we did in our study.

Although a cross-sectional retrospective study has some limitations, those were minimized in ours by standardization of data collection and objective definition of end-point. Other limiting factors included those described in the exclusion criteria. Also, we point out that our data were collected in only one center, with an urological residence program, where young surgeons are trained by professionals with excellency in $\mathrm{PNL}^{18}$.

In the present study, we observed that stone size and Guy Score are single predictive factors for success (stone-free). We also observed that stone size may influence success rate within each GS group, in special GS1. For other Guy groups, there were no statistical significant differences, but a tendency of higher chance of stone-free status, the smaller the stone size. This tendency may be confirmed in future studies increasing the size of the sample. A validated simple nephrometric system that takes into consideration the stone size, easily used, reproductible, with good correlation to success rate (stone-free) and PNL complication rate, will improve pre-operatory counseling of patients and resident capacitation.

\title{
R E S U M O
}

\begin{abstract}
Objetivo: verificar a associação entre taxa de sucesso de nefrolitotripsia percutânea, escore de Guy e tamanho do cálculo. Métodos: foram avaliados 100 pacientes submetidos à nefrolitotripsia percutânea. Todos os cálculos foram classificados de acordo com o escore de Guy. Consideramos o paciente livre de cálculos quando os fragmentos residuais fossem menores ou iguais a $2 \mathrm{~mm}$. Resultados: de acordo com o escore de Guy, 54\% tinham escore 1 (Grupo 1), 18\% escore 2 (Grupo 2), 15\% escore 3 (Grupo 3) e 13\% escore 4 (Grupo 4). Houve resolução de $77,77 \%$ no grupo 1 , de $27,77 \%$ no grupo 2 , de $26,6 \%$ no grupo 3 e de $7,69 \%$ no grupo 4 . Houve significância estatística para predição de taxa livre de cálculos entre os pacientes com escore de Guy 1 quando avaliados de acordo com o tamanho do cálculo. Entre os grupos 2, 3 e 4 não houve significância estatística, porém observamos tendência de que quanto maior o tamanho do cálculo, maior a chance de cálculo residual. Conclusão: a nefrolitometria pelo Escore de Guy e o tamanho do cálculo são preditores isolados para avaliação de sucesso da nefrolitotripsia percutânea. O tamanho do cálculo pode influenciar a taxa de sucesso de pacientes com Escore de Guy 1.
\end{abstract}

Descritores: Cálculos Renais. Nefrolitíase. Litotripsia. Pontuação de Propensão.

\section{REFERENCES}

1. Thomas K, Smith NC, Hegarty N, Glass JM. The Guy's stone score--grading the complexity of percutaneous nephrolithotomy procedures. Urology. 2011;78(2):27781.

2. Sinha RK, Mukherjee S, Jindal T, Sharma PK, Saha B, Mitra N, et al. Evaluation of stone-free rate using Guy's Stone Score and assessment of complications using modified Clavien grading system for percutaneous nephro-lithotomy. Urolithiasis. 2015;43(4):349-53.

3. Binbay $M$, Akman $T$, Ozgor F, Yazici O, Sari E, Erbin $A$, et al. Does pelvicaliceal system anatomy affect success of percutaneous nephrolithotomy? Urology. 2011;78(4):733-7.
4. Osther PJ, Razvi H, Liatsikos E, Averch T, Crisci A, Garcia JL, et al. Percutaneous nephrolithotomy among patients with renal anomalies: patient characteristics and outcomes; a subgroup analysis of the clinical research office of the endourological society global percutaneous nephrolithotomy study. J Endourol. 2011;25(10):1627-32.

5. Vernez SL, Okhunov Z, Motamedinia P, Bird V, Okeke Z, Smith A. Nephrolithometric Scoring Systems to Predict Outcomes of Percutaneous Nephrolithotomy. Rev Urol. 2016;18(1):15-27.

6. Fernström I, Johansson B. Percutaneous pyelolithotomy. A new extraction technique. Scand J Urol Nephrol. 1976;10(3):257-9.

7. Matlaga BR, Assimos DG. Changing indications of open 
stone surgery. Urology. 2002;59(4):490-3; discussion 493-4.

8. Wen CC, Nakada SY. Treatment selection and outcomes: renal calculi. Urol Clin North Am. 2007;34(3):409-19.

9. Smith A, Averch TD, Shahrour K, Opondo D, Daels FP, Labate G, Turna B, de la Rosette Jj; CROES PCNL Study Group. A nephrolithometric nomogram to predict treatment success of percutaneous nephrolithotomy. J Urol. 2013;190(1):149-56.

10. Okhunov Z, Friedlander JI, George AK, Duty BD, Moreira DM, Srinivasan AK, et al. S.T.O.N.E. nephrolithometry: novel surgical classification system for kidney calculi. Urology. 2013;81(6):1154-9.

11. Withington J, Armitage J, Finch W, Wiseman O, Glass J, Burgess N. Assessment of Stone Complexity for PCNL: a systematic review of the literature, how best can we Record Stone Complexity in PCNL? J Endourol. 2016;30(1):13-23.

12. Labadie K, Okhunov Z, Akhavein A, Moreira DM, Moreno-Palacios J, Del Junco $M$, et al. Evaluation and comparison of urolithiasis scoring systems used in percutaneous kidney stone surgery. J Urol. 2015;193(1):154-9.

13. Vicentini FC, Marchini GS, Mazzucchi E, Claro JF, Srougi M. Utility of the Guy's stone score based on computed tomographic scan findings for predicting percutaneous nephrolithotomy outcomes. Urology. 2014;83(6):1248-53.

14. Alobaidy A, Al-Naimi A, Assadiq K, Alkhafaji H, AlAnsari A, Shokeir AA. Percutaneous nephrolithotomy: critical analysis of unfavorable results. Can J Urol. 2011;18(1):5542-7.

15. Bozkurt $\mathbb{H}$, Aydogdu O, Yonguc $T$, Yarimoglu $S$, Sen V, Gunlusoy B, et al. Comparison of Guy and Clinical Research Office of the Endourological Society Nephrolithometry Scoring Systems for Predicting StoneFree Status and Complication Rates After Percutaneous Nephrolithotomy: A Single Center Study with 437 Cases. J Endourol. 2015;29(9):1006-10.

16. Tefekli A, Ali Karadag M, Tepeler K, Sari E, Berberoglu $Y$, Baykal $M$, et al. Classification of percutaneous nephrolithotomy complications using the modified Clavien grading system: looking for a standard. Eur Urol. 2008;53(1):184-90.

17. Dindo D, Demartines N, Clavien PA. Classification of surgical complications: a new proposal with evaluation in a cohort of 6336 patients and results of a survey. Ann Surg. 2004;240(2):205-13.

18. De la Rosette JJ, Laguna MP, Rassweiler JJ, Conort P. Training in percutaneous nephrolithotomy--a critical review. Eur Urol. 2008;54(5):994-1001.

Received in: 06/08/2017

Accepted for publication: 21/09/2017

Conflict of interest: none.

Source of funding: none.

\section{Mailing address:}

José Anacleto Dutra Resende Júnior E-mail: joseanacletojunior@gmail.com 